\title{
IDENTIFICAÇÃO DE ÁREAS SUSCEPTÍVEIS À DESERTIFICAÇÃO EM BACIA INTERMITENTE SAZONAL NO SEMI-ÁRIDO BRASILEIRO
}

\author{
IDENTIFICATION OF AREAS SUITABLE TO DESERTIFICATION IN SEASONAL INTERMITTENT BASIN \\ IN THE SEMI-ARID BRAZILIAN \\ IDENTIFICACIÓN DE ÁREAS VULNERABLES PARA EL DESETIZACIÓN EN LA CUENCA INTERMITENTE \\ ESTACIONAL EN EL BRASILEÑO SEMIÁRIDO
}

\author{
Flávio Rodrigues do Nascimento - UFF - Niterói - Brasil \\ flaviogeo@bol.com.br
}

\begin{abstract}
Resumo
0 presente trabalho tem como escopo avaliar as bases geoambientais, identificar e mapear as áreas degradadas susceptíveis à desertificação na Bacia Hidrográfica do Acaraú, na Região Nordeste do Brasil. A análise geoambiental integrada foi o norte metodológico perseguido. Usou-se, como procedimento técnico o processamento digital de imagens de satélite (TM e ETM + LANDSAT 5 e 7, cenas 217/63, 218/62 218/63. 1:250.000). A Bacia Hidrográfica foi destacada como unidade de planejamento e gestão geoambiental. As áreas mais susceptíveis a desertificação estão compreendidas nas unidades geoambientais da região de montante, médio-alto curso, em sertões semi-áridos. À jusante, no médio-baixo curso, embora predominem as formas agradacionais, notou-se que também há áreas sofrendo com mudanças ambientais, que podem comprometer a capacidade-suporte dos ecossistemas. Dados empíricos mostram que os impactos das atividades humanas sobre o ambiente físico se dão pela urbanização, desmatamento, irrigação, mudanças no uso da terra e mineração. Para combater a desertificação é necessário articular o conhecimento científico, políticas públicas com a ação das comunidades organizadas nesta bacia.
\end{abstract}

Palavras-chave: Desertificação. Semi-árido. Bacia intermitente sazonal.

\begin{abstract}
This research has the mainly objective to evaluate the geoenvironmental bases to identify and to map the suitable degraded areas to desertification in the Hydrographic Basin of the Acaraú River, in the northeast of Brazil. The integrated geoenvironmental analysis was the methodological north achieved. It was used as techniques the digital process of satelite images (TM e ETM+ LANDSAT data 5 e 7, scenes 217/63, 218/62 218/63. 1:250.000using Land-sat TM data). The river basin was improved as unit of planning and geoenvironmental management. The most suitable areas to desertification are in the geoenvironmental unit of upstream region, medium-high river in the semi-arid. Downstream, medium-down although it has with geomorphological process of accumulation it was observed that there are areas suffering with environmental changes that can damage the ecosystems. The detailed empirical investigations displayed that there are impacts humans activities on the physical environment happen about urbanization, deforestation, irrigation, land use changes and mining. For combat a desertification is need connecting science and publics politic with community-based organization action in this hydrographic basin.
\end{abstract}

Key words: Desertification. Semi-arid. Seasonal intermittent basin. 


\section{Resumen}

El actual trabajo tiene como objetivo evaluar las bases de los geoambientais, para identificar y a mapear los susceptíveis degradados las áreas al desertificação en el cuenca del Acaraú, en la región nordestal del Brasil. El análisis geoambiental integrado estaba el norte perseguido del metodológico. Uso como técnico del procedimiento el proceso digital de imágenes del satélite (TM y ETM+ LANDSAT 5 y 7, escenas 217/63, 218/62 218/63. 1:250.000). El cuenca fue separado como unidad del planeamiento y de la gerencia geoambiental. Las zonas propensas a la desertificación están incluidas en el unidades geoambientais en la región superior de los cursos de águas, arribamedio, en zonas semi-áridas del interior. Río abajo, medio-bajo y cursos, sin embargo las formas de los agradacionais predominan, notado que también tiene áreas el sufrir con los cambios ambiente, que pueden comprometer capacidad-apoyan de ecosistemas. Los datos empíricos demuestran que los impactos de las actividades humanas en el ambiente físico si elasticidad para la urbanización, la tala de árboles, la irrigación, los cambios en el uso de la tierra y minería. Para luchar el desertificação es necesario articular el conocimiento científico, política pública con la acción de las comunidades organizadas en este cuenca.

Palabras clave: Desertificación. Semi-áridas. Cuencas de temporada intermitente.

\section{Introdução}

Na perspectiva de amortizar a crescente degradação do meio físico, nas últimas três décadas foram iniciadas discussões sobre a temática ambiental, encerrando diagnósticos e estudos ambientais voltados a sua sustentação natural e social. Destaque a Conferência das Nações Unidas para o Meio Ambiente, em Estocolmo (1972), e a Conferência das Nações Unidades Sobre o Meio Ambiente e Desenvolvimento (Rio-92), no trato do desenvolvimento e meio ambiente.

Autoridades científicas e governamentais, bem como a mídia técnica e informacional, por meio destes eventos vêm discutindo e divulgando resultados de pesquisas sobre a degradação ambiental, sobretudo em ecozonas secas, no prisma da desertificação, enquanto um problema mundial de primeira magnitude (RUBIO, 1992, p. 20).

No capítulo 12.2, da Agenda 21, define a desertificação como sendo: "Degradação da terra nas regiões áridas, semi-áridas e subúmidas, resultantes de vários fatores, entre eles as variações climáticas e as atividades humanas”. No Brasil desde os primeiros estudos sobre este tema, em 1976 por Vasconcelos Sobrinho, até a Elaboração Programa Nacional de Combate à Desertificação e Mitigação dos Efeitos da Seca - PAN-Brasil em 2004, a Região Nordeste, principal no semi-árido, sempre foi destacada como foco para intervenções políticas e econômicas no tratamento da desertificação vinculada à seca. Assim, tem-se o desenvolvimento de uma macropolítica de trato da desertificação, com o escopo de atuar no combate a esta problemática nas áreas semi-áridas e subúmidas secas, áreas de entorno das áreas semi- 
áridas e subúmidas secas que ocorrem em algumas áreas do norte mineiro e capixaba, no Maranhão e, principalmente, no NE seco: as denominadas Áreas Susceptíveis a Desertificação (ASD’s).

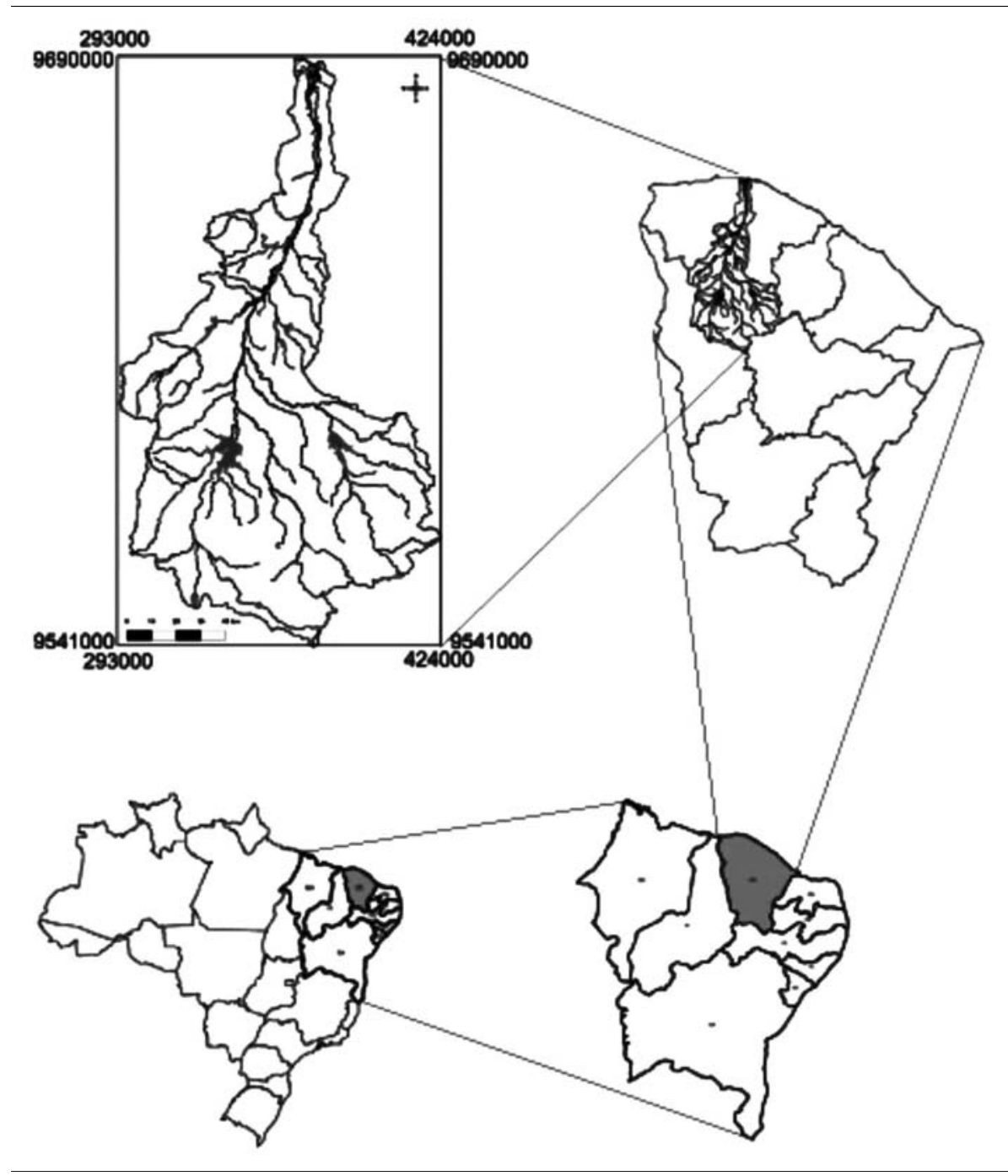

Figura 1: Bacia Hidrográfica do Acaraú, localizada no norte cearense. 
Neste contexto, o Estado do Ceará detém cerca de 92,1\% de seu território em áreas de clima semi-árido, isto é, $136 \mathrm{mil} \mathrm{km}^{2}$ dos $148 \mathrm{mil} \mathrm{km}^{2}$. Muito embora o fator Índice de Aridez (parâmetro mundial usado no estabelecimento de classes climáticas) busque enquadrar as áreas susceptíveis à desertificação, a maior parte da degradação ambiental ocorre mais por fatores humanos do que pela vulnerabilidade ambiental. Isto pode ser observado através de fatores empíricos, técnicos e teóricos na unidade de planejamento e gestão ambiental que é a Bacia Hidrográfica do Acaraú (B.H.A), objeto do presente estudo, localizada no norte cearense (Figura 1), em aproximadamente $15 \mathrm{mil} \mathrm{km} \mathrm{km}^{2}$, que desenvolve-se no sentido sul-norte, em aproximadamente $315 \mathrm{Km}$ de extensão, quando vai ter com seu nível de base, ou seja, o oceano Atlântico.

\section{Metodologia}

A linha teórico-metodológica seguida está fundamentada na visão holística, privilegiando a abordagem sintética e multicomposta, conforme a Teoria Geossistêmica de Bertrand (1968, p. 250), compreendida a luz da análise Geoambiental Integrada (SOUZA e OLIVEIRA, 2003, p. 97), respaldada nos estudos sociais e da natureza. Os componentes geoambientais correspondem aos fatores ambientais, físico-bióticos - suporte físico (condições geológicas e geomorfológicas), ao envoltório (condições hidroclimáticas) e à cobertura (solos e recobrimento vegetal) -, e humanos que promovem a dinâmica da paisagem. Com efeito, os domínios e as regiões naturais que compõem a B.H.A foram concebidas como sistemas ambientais, compostas por várias subunidades de paisagem, ou seja, geossistemas e geofácies. Foram identificadas por meio de trabalhos de sensores remotos e tiveram a capacidade de suporte dos recursos naturais assinaladas no conjunto de elementos ambientais, em termos de relação-integração, com mútua interação com as formas de uso e ocupação da terra, de maneira sistêmico-holística.

Em especial, as principais características naturais dominantes, sobretudo no que se refere ao estado de conservação da vegetação e o Índice de Aridez, foram os fatores primordiais na identificação e discriminação de classes de degradação ambiental que estão relacionadas à desertificação. Análises semi-supervisionadas de imagens de satélite e trabalhos de campo permitiram a visualização e estudo dos principais problemas ambientais. Como resultado final, obteve-se o Mapa do Estado de Conservação da 
Vegetação e Degradação/Desertificação. Cabe destacar que a razão entre a Precipitação e a Evapotranspiração Potencial (P/ETP) condiz com Índice de Aridez, enquadrando as áreas susceptíveis à desertificação, conforme as seguintes classes climáticas: hiper-árido: < 0,03; árido: 0,03-0,2; semi-árido: 0,21 - 0,50; subúmido seco: 0,51 - 0,65; subúmido úmido: $>0,65$, ou seja, apresenta ausência de aridez (NASCIMENTO, 2006, p. 37).

Porquanto, técnicas de sensoriamento remoto, com o processamento digital de imagens de satélite (cenas 217/63, 218/62, 218/63 dos satélites TM LANDSAT-5 e ETM + LANDSAT-7) possibilitaram a análise de uma cena em diversas regiões do espectro eletromagnético, ao passo que integra vários dados georeferenciados. Essas imagens foram tratadas no software ENVI v.3.6 e pelo módulo de sensoriamento remoto do SPRING v.3.6. Seu georeferenciamento ocorreu com a utilização de pontos de controle retirados nas cartas de 1:100.000 (DGS), como também adquiridas e retificadas ou ratificadas por GPS.

Portanto, após a identificação, qualificação e cartografação das áreas susceptíveis e/ou em processo de degradação/desertificação, produziu-se o mapa supracitado, tendo como pressuposto básico a concepção holística do meio ambiente, conforme as condições de potencialidades e de limitações de uso e ocupação das unidades de paisagem, destacando os ecossistemas frágeis mais vulneráveis.

\section{Bacia Hidrográfica do Acaraú: sinopse dos atributos geoambientais}

Na B.H.A, historicamente, a exemplo do que ocorreu em grande parte do nordeste setentrional, foram deflagradas fortes pressões sobre os recursos naturais a partir de uma relação sociedade versus natureza conflituosa, ao lume de políticas piegas. Em certos casos, são visíveis as marcas deste problema no conjunto dos fatores bióticos e abióticos que compõem unidades ambientais. Sendo que tais problemas são agravados por conta de seu quadro geoambiental vulnerável, onde principalmente os recursos de água, solo e geobotânico são consumidos e exauridos vorazmente, sob a atual conjuntura política e econômica. Desta feita, a susceptibilidade às contingências climáticas e a vulnerabilidade às secas são magnificadas.

Todavia, o processo de degradação ambiental no Ceará ocorre mais pelas intervenções socioeconômicas e culturais do que pelos fatores ambientais e sua dinâmica natural. A não observância de políticas regradas 
na gestão territorial, e em especial de formas conservacionistas no uso e ocupação da terra, tendem a produzir sérios problemas de deterioração ambiental, que ponham em risco a capacidade produtiva dos solos e a qualidade ambiental.

A ecofiográfica da B.H.A, entretanto, está em função de arranjos entre o potencial ecológico, exploração biológica e as formas de uso/ocupação da terra. Neste aspecto, é possível afirmar que as condições geomorfológicas e climáticas assumem destaque em relação à fisiologia da paisagem. Sob irregularidades pluviométrica, com escassez, retardos ou ausência (secas), principalmente nas áreas dos sertões, em condições subequatoriais no trópico semi-árido, o clima regional representa fator de destaque no quadro geoambiental. Os processos morfogenéticos, portanto, são majoritariamente físicos; a drenagem superficial é composta por rios intermitentes e o potencial hidrogeológico só chega a ser representativo nas áreas de deposição litorâneas e pré-litorâneas; e, os afloramentos rochosos e solos imaturos são comuns.

Para a biodiversidade, o fator que melhor lhe retrata é a resposta geobotânica das caatingas, florística e fisionomicamente adaptadas às contingências climato-hidrológicas. No entanto, o porte dos indivíduos vegetacionais eleva-se em razão de efeitos orográficos (serras úmidas e subúmidas), melhoria das condições de potencialidades edafológicas (Argissolos Eutróficos e Luvissolos) e proximidade das planícies fluviais dos rios Acaraú e principais tributários, onde pode ser destacada a mata ciliar florestal, inclusive de carnaúba (Copernicia cerifera), espécie endêmica do nordeste brasileiro.

As áreas litorâneas e pré-litorâneas exibem feições de acumulação, respectivamente, com sedimentos arenoquartzosos nas praias, dunas, planície flúvio-marinha e areno-argilosos da formação barreiras nos tabuleiros costeiros, todos cenozóicos. Os neossolos quartzarênicos ocorrem na planície litorânea, sendo que gleissolos sálicos distribuem-se nos manguezais e argissolos acinzentados nos tabuleiros costeiros. Estes aspectos mostram nas áreas terminais da bacia que homogeneidade paisagística não é regra.

As formas de ocupação da terra ocorrem com o turismo, carcinicultura, maricultura e extratismo vegetal na costa da bacia, enquanto a agricultura de subsistência e o agro-extrativismo são usuais nos tabuleiros.

As serras e cristas residuais como a meruoca, machado e das matas, exibem compartimentos do relevo, enquanto elementos diferenciadores do clima regional, ao tempo que as chuvas são das mais abundantes da bacia, e os solos são de boa fertilidade natural (argissolos eutróficos) sob substrato do complexo cristalino pré-cambriano deformados por tectonismo oriundos 
dos processos de erosão seletiva. Nestas feições do relevo o revestimento vegetal é mais frondoso, com indivíduos perenifólios, com enclaves originais da Mata Atlântica. Entretanto, o uso e ocupação do solo são intensivos nas serras úmidas com sítios e chácaras, queimadas - a exemplo do que ocorre em toda bacia -, e a agricultura itinerante intensificam os efeitos erosivos. E como testemunho da geomorfogênese pliocênica, os knicks de inselbergs e os pequenos maciços sertanejos elevam-se como pontos rochosos em meio aos sertões aplainados.

As áreas de drenagem, ainda, entrecortam o "front" central da Cuesta da Ibiapaba. Trata-se de um planalto sedimentar silúrio/denoviano, com arenitos grosseiros, conglomeráticos, siltitos e folhelhos em estratificação cruzada. Neste planalto ocorrem os solos mais antigos da bacia, os latossolos, além de argissolos que são revestidos por mata úmida. É uma área muito procurada para fruticultura e lavouras de subsistência.

Completando o quadro de diversidade geoambiental, as depressões periféricas da Ibiapaba e do Centro-Norte do Ceará comprovam a diversificação de espaços ecológicos. Apresentam geologia do complexo cristalino pré-cambriano com predominância de rochas do complexo nordestino, sobretudo com gnaisses e migmatitos. Formam superfícies pediplanadas, eventualmente dissecadas e feições de topos convexos e tabulares, intercalados por vales com fundos planos capeados por sedimentos aluviais das planícies fluviais. O material de alteração e as condições bioclimáticas, originaram luvissolos (a classe que detém a primazia em todo o vale), planossolos, neossolos litólicos e regolíticos, afloramentos de rochas, além de neossolos flúvicos.

Os sertões semi-áridos são revestidos, originalmente, por espécies das caatingas arbustivas ou abertas e arbóreas, e foram historicamente ocupados pela pecuária extensiva, agricultura de subsistência com milho, feijão e mandioca, e o agro-extrativismo. As políticas equivocadas de combate às secas, em detrimento a convivência com esse fenômeno, a pobreza e falta de incentivo técnico ao produtor rural concorrem para um sistema de incorporação de terras, queimadas intensas e a utilização de técnicas rudimentares. Isto provoca ablação dos solos, definhamento de mananciais e intensificação de processos erosivos, com o consequente assoreamento dos talvegues.

São nos sertões que as marcas das intervenções deliberadas das atividades socioeconômicas são mais evidentes enquanto processos de degradação/desertificação. Nos sertões de Santa Quitéria e do rio Groaíras o tratamento das imagens de satélite associadas às checagens da verdade ter- 
restre confirmam que estes setores estão entre os mais degradados/desertificados em toda bacia, logo seguidos das serras subúmidas secas.

\section{Degradação ambiental e desertificação}

A degradação que pode culminar com a desertificação deriva das atividades humanas inadequadas sobre os mosaicos paisagísticos já fragilizados. Dessa forma, as condições econômicas e sociais podem potencializar a desertificação. A degradação ambiental inconseqüente estiola os geoambientes causando a destruição de significativa parcela dos recursos naturais e pauperização dos setores econômicos baseados nas atividades agrárias. Dessa forma, a perda da capacidade produtiva dos sistemas econômicos, reflete-se em perda da identidade cultural, processo de migração populacional, empobrecimento social.

Com o empobrecimento dos múltiplos níveis dos componentes da biosfera, associados à semi-áridez, ocorrem sinais claros de esgotamento dos recursos naturais em diversos sistemas ambientais que compõem as bacias, sobretudo nos sertões, com evidências de desertificação.

Com efeito, a B.H.A concentra suas áreas de drenagens em ASD's, conforme o PAN-Brasil. Agravante a esse fato é que outros estudos consideram haver nessa unidade de gestão e planejamento ocorrência de desertificação em níveis grave a muito grave em relação ao contexto brasileiro (MMA, 2002), devido às atividades socioeconômicas desregradas (NASCIMENTO 2006: 53), onde sobressai o desmatamento indiscriminado. Ou mesmo considerando o Índice de Aridez, com porções nas classes medianamente críticas $(0,41-0,45)$ e menos críticas $(0,46-0,50)$ (LEITE et al., 1993: 157).

Sobre estes aspectos, ocorre um eixo aproximado de Nordeste-Sudoeste denominado por Conti (2002) de Diagonal Árida do Ceará. Estende-se desde Itapaje, a sotavento do Maciço de Uruburetama, no norte, até Campos Sales, no sopé da Chapada do Araripe, no sul desse Estado. Entretanto, como principal resultado do estudo executado, observou-se que quanto às classes de estado de conservação da vegetação, a bacia concentram diferentes níveis, pelo menos foram classificadas 5 unidades de classes, a saber: Conservada, Parcialmente Degradada, Degradada, Fortemente Degradada e Solo exposto. É lamentável observar que todos os complexos vegetais apresentam avançados estágios de degradação ambiental que levam aos problemas de desertificação. 
Desta maneira, para efeitos de compartimentação ambiental que apresente a degradação das paisagens, associando-se o estado de conservação vegetacional aos sistemas ambientais, solos e ao Índice de Aridez, considerando o próximo mapa, tem-se que:

- As planícies fluviais com Matas ciliares x neossolos flúvicos, variam das classes conservada a solos expostos.

- Os Sertões da depressão periférica da Ibiapaba e do Acaraú com Caatingas das depressões sertanejas x luvissolos, argissolos, planossolos, neossolos litólicos estão degradados apresentando solos expostos.

- Os Maciços residuais das serras do Machado, das Matas, do Pajé, das Cobras e outras com neossolos litólicos, argissolos, luvissolos, capeados por todas as variações fisionômicas e florísticas das Caatingas das depressões sertanejas, apresentam-se com degradação intensa variando de parcialmente degradada à exibição de solo exposto. E nas serras úmidas e subúmidas, em topografia mais acentuada, a degradação da vegetação de enclaves úmidos varia de parcialmente degradada à exibição de solo exposto. Por isto apresenta a maior variação de classes de degradação.

Para um esboço das considerações retromencionadas, a Figura 2 apresenta as áreas degradadas/desertificadas em relação ao estado de conservação da vegetação.

\section{Últimas observações}

No contexto da desertificação, os ecossistemas de terras secas têm estratégias de adaptação às severidades climáticas. No caso das caatingas, são comportamentos naturais miméticos, como mecanismo de defesa (recursos de sua capacidade-suporte) em virtude do balanço hídrico negativo para ajustes ecológicos que ocorrem sob aspectos morfológicos, anatômicos e fisiológicos (Quadro 1). A caducifólia, por exemplo, diminui a evapotranspiração e impede a realização de processos fotossintéticos, mantendo um equilíbrio latente, vital aos vegetais. $\mathrm{E}$ as altas temperaturas predominantes podem limitar o desenvolvimento da vegetação. Adaptadas às condições fotoperiódicas, a transpiração vegetal compensa o aquecimento dos tecidos mediante de perdas pela evaporação. 


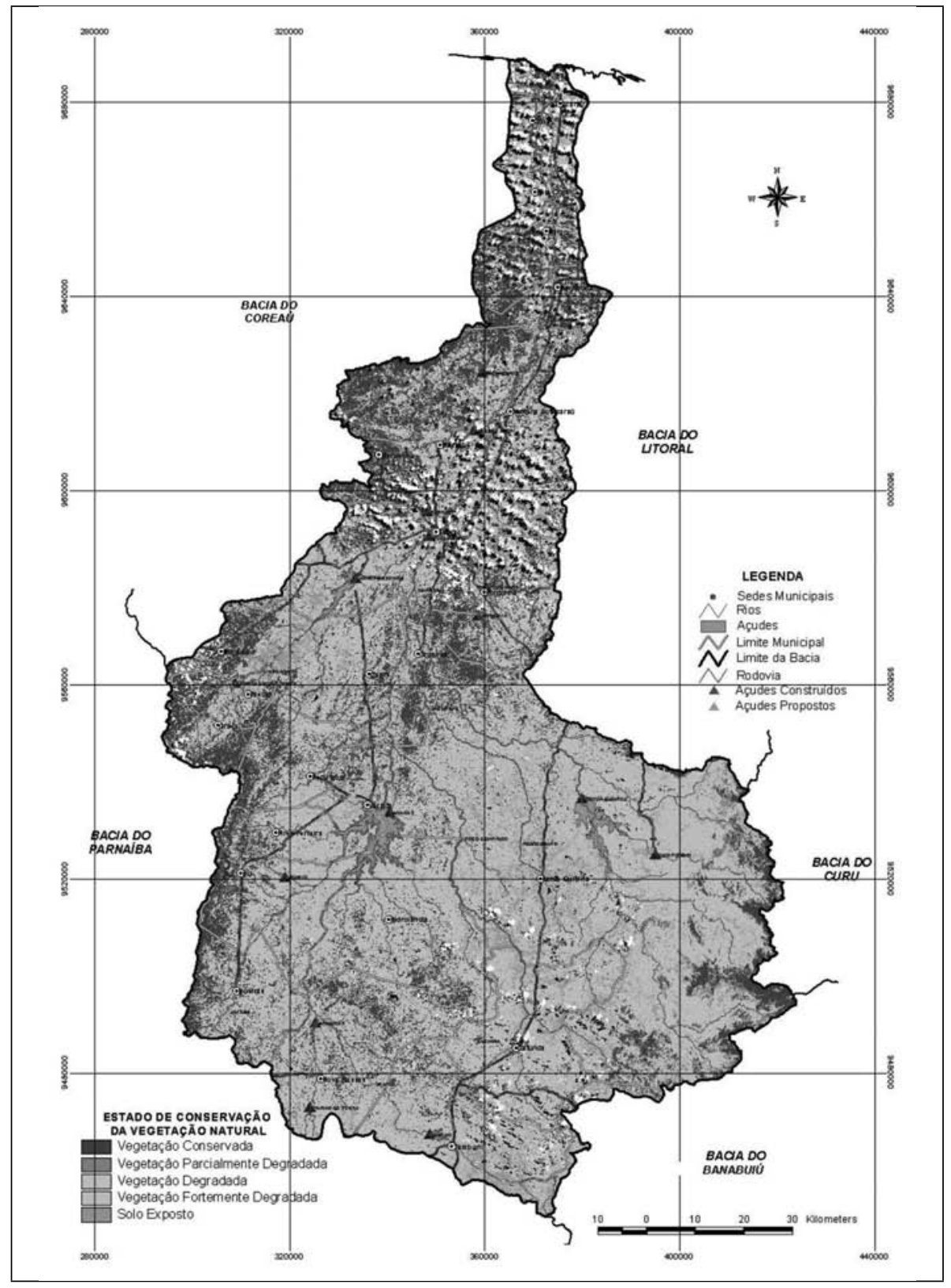

Figura 2: Estado de conservação da vegetação e áreas degradadas/desertificadas na Bacia do rio Acaraú. 
Quadro 1: Principais aspectos de ajustes ecológicos das caatingas.

\begin{tabular}{|c|c|c|}
\hline Aspectos Morfológicos & Aspectos Anatômicos & Aspectos fisiológicos \\
\hline $\begin{array}{l}\text { - Afilia, total expressão xero- } \\
\text { mórfica sem qualquer vitalida- } \\
\text { de aparente; } \\
\text { - Órgãos hipógeos tuberizados } \\
\text { ou xilopódios; } \\
\text { - Folhas pequenas ou compos- } \\
\text { tas; } \\
\text { - Plantas espinescentes ou acu- } \\
\text { leadas; } \\
\text { - Intumescência caulinar (bar- } \\
\text { rigudas); } \\
\text { - Cladódios carnoso-suculentos } \\
\text { (cactáceas) }\end{array}$ & $\begin{array}{l}\text { - Cascas finas e lisas; } \\
\text { - Lignificação precoce e inten- } \\
\text { sa; } \\
\text { - Estrutura radicial destinada à } \\
\text { acumulação de reservas nutri- } \\
\text { tivas (amido, açúcares etc.); } \\
\text { - Grande número de estômatos } \\
\text { nas folhas, como mecanismo } \\
\text { estrutural ao controle da trans- } \\
\text { piração. }\end{array}$ & $\begin{array}{l}\text { - Mecanismo para reduzir a } \\
\text { perda de água (dobramento ou } \\
\text { disposição das folhas para di- } \\
\text { minuir a transpiração); } \\
\text { - Germinação rápida das semen- } \\
\text { tes; } \\
\text { - Alta velocidade de brotação e } \\
\text { de floração; } \\
\text { - Intensa atividade clorofiliana; } \\
\text { - Funcionamento estomático, re- } \\
\text { gulando a transpiração; } \\
\text { - Caducifolia na estação seca; } \\
\text { - Geralmente apresenta revesti- } \\
\text { mento de cera nas folhas. }\end{array}$ \\
\hline
\end{tabular}

As condições edáficas diferenciam os processos de resiliência. Por outro lado, o retorno às condições originais, possivelmente, não será atingido em razão do: desaparecimento das espécies de matas; predação seletiva e constante do homem; rarefação da fauna, que não regula mais a dispersão e reprodução das espécies vegetais. Essa degradação, em parte, é impulsionada pelo fato de a matriz energética do Ceará, durante muitos anos, estar assentada nos recursos florestais (lenha e carvão vegetal). Nada obstante, as rupturas do equilíbrio ambiental nos diferentes geossistemas, que contingenciam a capacidade de suporte geoambiental, está pautada na degradação dos solos, das águas e da vegetação.

A degradação dos solos, em grande parcela, é seguida ou antecedida pelo desmatamento indistinto através do modus operandi impróprios dos pequenos produtores e assentados rurais, à falta de incentivo à produção agrícola. É justo revelar que muitas vezes são responsabilizados por toda ordem de degradações ao ambiente, em detrimento do agronegócio exportador, que também não é menos degradante e não tem nada de "inocência”. Nesta asserção, ao assinalar que as comunidades que vivem em frágeis estruturas socioeconômicas, embora bem adaptadas ao próprio meio, são afetadas pelo contato com tecnologias avançadas.

Meios e técnicas de proteção ambiental adequados, que busquem, principalmente, controlar a pressão dos rebanhos, facilitariam a reabilitação dos vegetais próximos ao clímax. Ademais, a instituição e a manutenção de unidades de conservação seguirão esses princípios. 


\section{Referências}

BRASIL, Ministério do Meio Ambiente (MMA). Programa de Ação Nacional de Combate à Desertificação e Mitigação dos Efeitos da Seca, PAN-BRASIL. Edição Comemorativa dos 10 anos da Convenção das Nações unidades de Combate à Desertificação e Mitigação dos Efeitos da Seca - CCD. Brasília: MMA, 2004. 225p.

BERTRAND, Georges. Paysage et Géographie Physique Global. Esquisse Méthodologique. In: Revue Géographique dês Pyrenées et du Sud Ouest. Toulouse, France. 39(3). p. 249-272. 1968.

LEITE, Francisco R.; Soares, Ana M. L. \& Martins, Maria Lúcia R. Áreas Degradadas Susceptíveis aos Processos de Desertificação no Estado do Ceará - $2^{\mathrm{a}}$ Aproximação. In: Anais do VII simpósio brasileiro de sensoriamento remoto. Curitiba - PR, 1993. p. 156-162.

NASCIMENTO, Flávio R. do. Degradação ambiental e desertificação no Nordeste Brasileiro: o contexto da Bacia Hidrográfica do rio Acaraú - CE. 2006. 325p. (Tese de doutorado em Geografia). Instituto de Geociências, UFF: Niterói, 2006. 19/04/2006.

. Programa de Ação Nacional de Combate à Desertificação no Brasil (PAN-BRASIL) e o Bioma Caatinga. In: Anais del $12^{\circ}$ encuentro de geógrafos de américa latina. Universidad de la República: Montevideo. 2009. Disponível em: <http://egal2009.easyplanners.info/ Uruguay $>$.

RUBIO, Jose L. Desertification: Definiciones. Marco Conceptual. In: Seminário Desertificación y Cambio Climático. Centro de Investigaciones sobre Desertificación - CIDE/Universidad Internacional Menendez Pelayo (UIMP), C.S.I.C - Valencia. 1995. 46p.

SOUZA, Marcos J. N. \& OLIVEIRA, Vládia P.V. Physical and Environmental Context In: The State of Ceará. In: KROL, Thomas G. e ARAÚJO, H. Frischkorn (Editors). Global Change and Regional Impact: water availability and vulnerability of Ecosystems and Societ. Berlin; Heidelberg; New York; Hong Kong; London: Milan: Paris; Tokyo: Springer, 2003. p. 95-104.

Flávio Rodrigues do Nascimento - Professor Adjunto da Universidade Federal Fluminense.

Recebido para publicação em Outubro de 2009 Aceito para publicação Dezembro de 2009 